\title{
An analysis on satisfaction level of clinicians on implant surgical guidance system based on computed tomography
}

\author{
Min-ho Hong ${ }^{\dagger}$, Ming-Xu Jin ${ }^{\dagger}$, Du-Hyeong Lee, Kyu-Bok Lee* \\ Department of Prosthodontics, College of Dentistry and Advanced Dental Device Development Institute, Kyungpook National \\ University, Daegu, Republic of Korea
}

Purpose: The purpose of this study was to conduct a comparative assessment on the satisfaction level for the two interfaces of surgical guide system (SimPlant and R2GATE), the design and convenience of manufactured surgical guides and the importance of using the surgical guides thereof by means of survey. Materials and Methods: Hereupon, they simulated the implant surgical process by mounting the two manufactured systems of surgical guide on a dental mold, respectively. The study subjects were instructed to complete the questionnaire as to the satisfaction level upon completion of the simulated surgery. This study summarized the data of each question after collecting the completed questionnaires. Then, this study analyzed the summarized data by utilizing statistical program SPSS 20.0 (IBM). Results: R2GATE had a higher value of the satisfaction level on the design and convenience of manufactures surgical guides. R2GATE group $(7.33 \pm 1.26)$ was found to have a higher value in terms of the overall satisfaction level compared to SimPlant group $(6.67 \pm 1.26)(\alpha=0.05)$. Conclusion: The user satisfaction level on the surgical guide manufactured for R2GATE system was to such an extent as it can be widely used in clinical environment. Moreover, the surgical guide manufactured as R2GATE system can guide both the length and direction of a drill simultaneously. As a result, it is highly recommended for those beginners who do not have a lot of experience in implant placement. (J Dent Rehabil Appl Sci 2015;31(3):178-85)

Key words: surgical guide; implant guide system; survey

\section{서론}

컴퓨터 단층촬영 (computed tomography, CT)은 Hounsfield $^{1}$ 에 의해 개발되어 1973년도 British journal of radiology에 발표되었다. 이후 1970년대부터 의학적 으로 사용하기 시작하였다. 약 10 여년 전 부터 치과영역 에 CT가 도입되면서 구강악안면의 해부학적 구조에 대 한 3차원적인 영상을 얻을 수 있고 보다 정확한 진단과 치료를 위한 접근을 이룰 수 있어 비약적인 발전을 가져 왔다. 그러나 CT는 경제적 부담이 크고 방사선 피폭량이

*Correspondence to: Kyu-Bok Lee

Professor, Department of Prosthodontics, School of Dentistry, Kyungpook National University, 2177 Dalgubeoldae-ro, Jung-gu, Daegu, 41904, Republic of Korea

Tel: +82-53-600-7674, Fax: +82-53-426-7661, E-mail: kblee@knu.ac.kr

Received: May 26, 2015/Last Revision: July 23, 2015/Accepted: July 27, 2015

†These authors contributed equally to this work.
크다는 문제점을 가지고 있다. ${ }^{2}$ 이는 cone-beam 컴퓨터 단층촬영(cone-beam CT, CBCT)가 개발된 계기가 되었 다. CBCT는 일반 CT와 비슷한 이미지를 제공할 수 있고 방사선 피폭량이 CT보다 작아 치과영역에서 점점 일반 화 되었다. ${ }^{3}$

종래의 수술용 가이드(surgical guide)는 환자의 구강내 의 인상을 채득하고 모형을 제작한 후 폴리머(polymer) 로 환자의 치아, 조직 등에 의해 지지될 수 있게 제작하 였다. Becker 등 ${ }^{4}$ 은 수술용 가이드를 대신해서 진공성형 템플릿(vacuum-formed templates)을 이용하는 방법을

Copyright@ 2015 The Korean Academy of Stomatognathic Function and Occlusion. (c) It is identical to Creative Commons Non-Commercial License. 
제시하였고 George 등 ${ }^{5}$ 은 자가 중합 레진을 이용하여 수술용 가이드를 제작하였다. 이러한 전통적인 방법으 로 제작된 가이드는 임플란트 식립 위치나 방향이 이상 적이지 않을 수 있으며, 수술용 가이드 제작 시 컴퓨터 단층촬영 영상을 활용할 수 없었다.

1990년대에 이르러 CAD/CAM을 기반으로 한 임 플란트 가이드 시스템의 소개와 함께 CT 영상과 치 아 모형의 스캔파일을 적용하여 인공치근(fixture)의 식립 방향과 위치를 디자인한 후, 쾌속 조형법(rapid prototyping, RP)을 이용하여 수술용 가이드를 제작하 고 임플란트 수술에 이용할 수 있었다.

임플란트 식립에 이용되는 가이드 시스템은 기술 의 발전으로 인해, 시중에 많은 종류의제품이 등장하 고 있으나 최근 해외의 문헌들을 살펴보면 Simplant (Materialise Dental, Leuven, Belgium), Nobelguide ${ }^{\text {TM }}$ (Nobelbiocare, Gothenburg, Sweden) 등 임플란트 가이 드 시스템이 자주 소개된다.

Nobelguide 시스템의 특점은 수술용 템플렛을 치조 골에 연결할 수 있는 고정핀을 가지고 있지만, Simplant 시스템의 경우 고정핀이 없으므로 수술용 템플렛의 안 정성이 낮아져 식립할 때 오차가 발생할 수 있다. 그러 나 Simplant 시스템은 인공치근 식립을 위한 치조골 삭 제용 드릴(pilot drill)과 모든 과정을 유도하는 슬리브 (sleeve)가 디자인되어 있어 보다 높은 안정성을 보완시 켜 준다.

Simplant 시스템의 슬리브가 임플란트 식립의 방향만 유도하고 깊이는 제어하지 않는 문제점과 가이드 제작 을 해외에 의뢰해야 하는 등 번거로움을 감안하여 최근 국내에서는 R2GATE (Megagen Implant, Gyeongsan, Korea)라는 시스템을 출시하였다.

이러한 수술용 가이드는 수술 전 치료 계획을 기반으 로 컴퓨터 상에서 수술 부위에 대한 가시적인 진단이 가 능하므로 골질이 부족한 부위를 피할 수 있고, 정확한 식립 위치를 결정할 수 있는 장점이 있다.

기존 문헌들을 살펴보면 Valente 등 $^{6}$ 의 사체연구와 Ruppin 등 ${ }^{7}$ 의 임상연구에서 Simplant 시스템으로 제작
한 수술용 가이드의 정확도에 대한 비교연구를 시행하 였다. 최근 Park 등은 초창기 수술용 가이드 시스템인 SimPlant와 국내에서 개발된 R2GATE를 포함한 총 6가 지의 서로 다른 수술용 가이드 시스템의 드릴(Drilling) 과 애관(Bushing) 사이의 간격에 대해 비교하였다.

대부분의 선행연구에서 임플란트 식립 전, 후의 CT 영상을 중첩시키고 분석하는 방식으로 수술용 가이드 시스템의 정확성을 검증하였다. 이와 같이 보고되고 있 는 연구는 SimPlant 시스템을 기준으로 비교 평가하는 연구가 주로 보고되고 있었다. 그러나 임플란트 가이스 시스템의 사용 편의성과 디자인을 고려했을 때, 사용자 의 평가에 대한 연구는 많지 않고 국내 프로그램과 비교 하는 연구는 미비하다.

따라서, 본 연구에서는 SimPlant와 R2GATE 두 가지 수술용 가이드 시스템의 인터페이스 만족도, 제작된 수 술용 가이드의 디자인과 편의성, 수술용 가이드 활용 시 중요도에 대한 만족도를 설문 조사하여 비교 평가 하고 자 하였다.

\section{연구 재료 및 방법}

\section{1. 연구 대상}

경북대학교치과병원 치과의사 12 명을 대상으로 설문 지를 통해 임플란트 가이드 시스템과 제작된 수술용 가 이드의 디자인, 편의성 및 전체 만족도를 직접 체크하는 방식으로 응답하도록 하였다. 치과전문대학원 과정을 수료하고 치과대학병원에 근무하는 자를 선정기준으로 하였고, 치과전문대학원 과정을 수료하지 아니 한 자는 제외하였다. 또한, 본 연구는 경북대학교병원 임상시험 심사위원회의 심의를 거쳐 승인(KNUH 2014-11-020) 을 받고 진행하였다.

Table 1은 연구에 사용되어진 SimPlant (Materialise Dental, Leuven, Belgium)와 R2GATE (Megagen Implant, Gyeongsan, Korea) 프로그램을 보여준다.

Table 1. Technical data for two different system

\begin{tabular}{ccccc}
\hline Manufacturer & Software & Compatible with implant brands & Drill direction guidance & Drill length guidance \\
\hline Materialise Dental & SimPlant & More than 20 & Yes & No \\
Megagen Implant & R2GATE & Only Megagen & Yes & Yes \\
\hline
\end{tabular}




\section{2. 연구 방법}

1) 임플란트 식립계획 프로그램

본 연구에서는 술자를 대상으로 두 종류의 임플란트 가이드 시스템의 사용방법에 대한 교육을 진행하고 무 작위로 임플란트 식립이 필요한 환자 1 명을 선정하여 연구 목적과 과정을 설명하고 환자의 충분한 이해와 동 의를 바탕으로 하여 시행되었다.

환자의 수술 부위에 대한 가시적인 진단을 하기 위 해 환자의 CT 촬영, 인상채득 과정이 시행되었다. 채득 한 인상으로부터 치아모형을 제작하고 탁상용 스캐너 (Ceramil Map400, AmannGirrbach, Koblach, Austria) 로 치아모형을 스캔하여 디지털화 하였다. 앞에서 얻은 CT 영상과 치아모형 영상을 각각 두 종류의 임플란트 가이드 시스템에서 불러온 후 술자가 직접 임플란트 수 술 과정을 프로그램 상에서 모의하고 디자인하였다(Fig. 1).

\section{2) 수술용 가이드 제작}

술자는 각 시스템으로 제작된 수술용 가이드를 외형 상 서로 구별할 수 있지만 브랜드는 구별하지 못하는 상 태에서 다음 두 가지 수술용 가이드를 치아모형에 각각 장착한 상태에서 임플란트 수술 과정을 모의하였다(Fig. 2). 본 연구에 사용된 두 가지 수술용 가이드는 각기 본 사에 환자의 CT 파일과 모형스캔 파일을 의뢰하여 제작 하였다.

\section{3) 비교평가 및 설문지 작성}

프로그램 상과 치아모형 상에서 각각 임플란트 수술 모의과정을 마친 뒤 술자에게 프로그램의 인터페이스 만족도, 제작된 수술용 가이드의 디자인과 편의성, 수술 용 가이드 활용 시 중요도, 전체 만족도에 관한 설문지 를 나눠주고 작성하도록 하였다; 설문지의 각 항목에 대 한 술자의 만족도를 해당 척도 수준에서 새로 부여된 알 파벳(a: SimPlant, b: R2GATE)을 체크하도록 하였다.
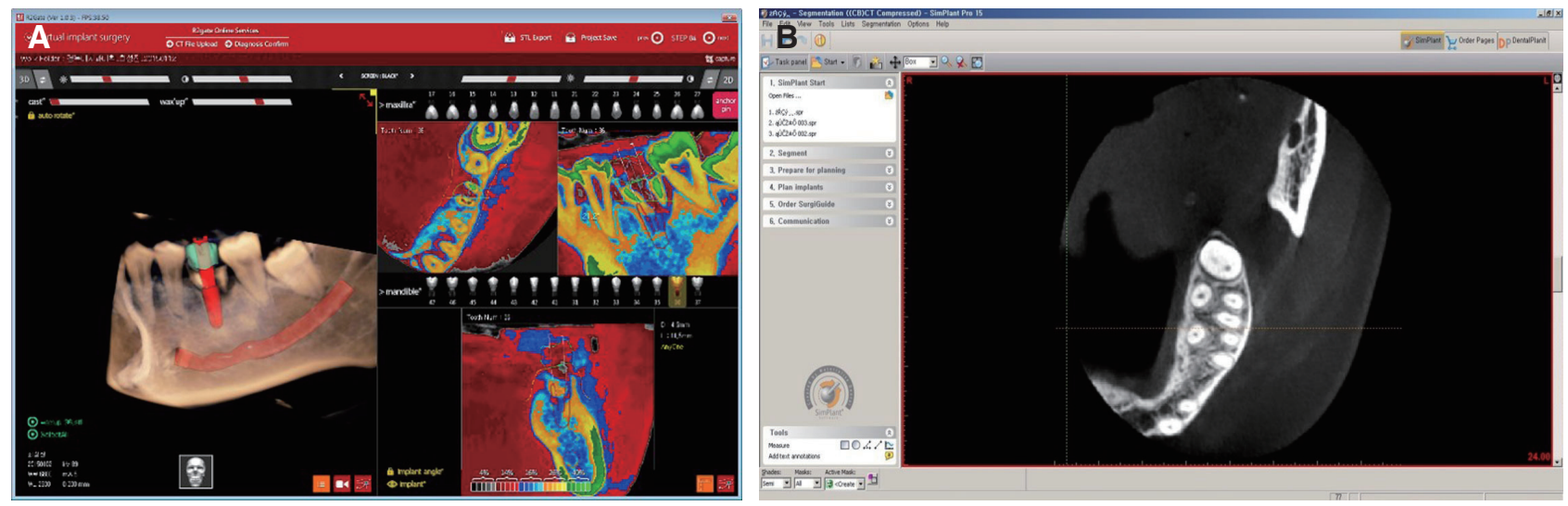

Fig. 1. (A) Surgical guide program SimPlant interface, (B) Surgical guide program R2GATE interface.
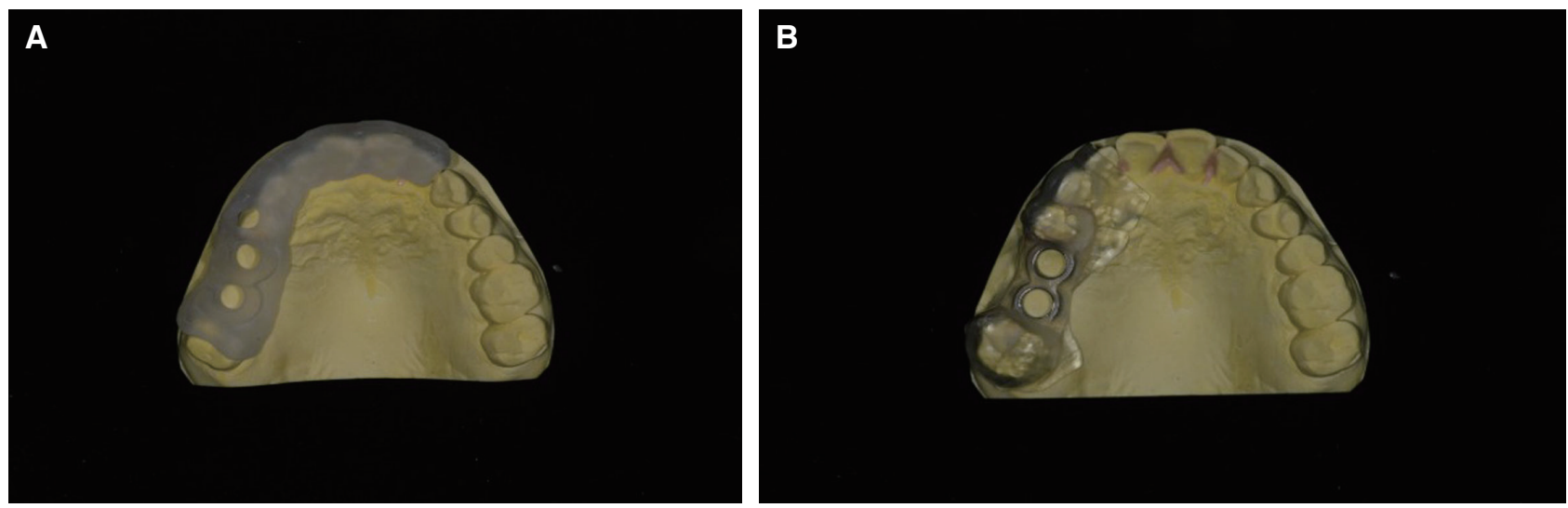

Fig. 2. (A) Place SimPlant system surgical guide on the model, (B) Place R2GATE system surgical guide on the model. 


\section{3. 설문항목 개발}

1) 임플란트 가이드 시스템의 디자인과 편의성

프로그램에 대한 디자인과 편의성 설문은 총 10 문항 으로 구성되었고 각 설문 항목 문항에 대한 만족도를 Likert의 5점 척도를 이용하여 '매우 그렇다', '그렇다', '보통이다', '그렇지 않다' , '전혀 그렇지 않다’ 로 나누 어 각각 5점, 4점, 3점, 2점, 1점으로 정하고 만족도는 점 수가 높을수록 좋은 것으로 해석하였다. ${ }^{9}$

2) 각 시스템으로 제작된 수술용 가이드의 디자인과 편의성

두 가지 시스템으로 제작된 수술용 가이드의 디자인 과 편의성 설문은 5 문항으로써, 동일하게 Likert의 5점 척도를 사용하였다.

\section{3) 수술용 가이드의 활용 시 중요하다고 생각되는 우} 선 순위

수술용 가이드을 이용하여 임플란트 수술 시행 시 술 자가 중요하다고 생각할 수 있는 문제를 '프로그램에서 디자인 용이성', ‘수술 시 가이드의 장착 용이성', ‘임 플란트의 식립 정확성', ‘수술 간편성의 증진', '가이 드 시스템의 비용' 등 5 개 문항으로 나누었고 동일하게 Likert의 5 첨 척도를 이용하였다.

\section{4) 전체 만족도}

마지막으로 수술용 가이드 시스템의 전체적인 디자인 과 편의성에 대한 술자의 전체 만족도를 1점부터 10점 까지 10 개 등급으로 나누어 기록하였다.

\section{4. 설문지 정리 및 통계 분석}

작성된 설문지를 회수하여 각 문항에 대한 데이터 를 정리하고 통계 프로그램 SPSS 20.0 (IBM, Chicago, $\mathrm{USA}$ )를 이용하여 분석하였다. 두 그룹 간 차이를 확 인하기 위해 독립표본 t-test를 이용하였고 유의수준은 0.05 로 설정하였다.

\section{결과}

임플란트 가이드 시스템의 디자인과 편의성 만족도 결과에서 “CT 모형의 정합 편의성”에서 R2GATE 군 (3.912 \pm 0.87$)$ 이 SimPlant 군(3.50 \pm 0.97$)$ 보다 유의하 게 높은 값을 나타냈다 $(P<0.05)$. "디자인가이드 제작 을 위한 파일전송 편의성”, “제조사별 임플란트 선택의 편의성”, “이미지 형성과 크기와 모양의 조절 편의성" 등의 부분에서 SimPlant 군이 더 높은 점수를 받았다 $(P$ $<0.05$, Table 2, Fig. 3).

각 시스템으로 제작된 수술용 가이드의 디자인과 편 의성 만족도 결과는 "두 가지 시스템에서 제작된 가이

Table 2. Subjects on the evaluation to the design and ease of surgical guide making program.

\begin{tabular}{|c|c|c|c|c|c|c|}
\hline \multirow{2}{*}{ Option } & \multirow{2}{*}{ Composition } & \multicolumn{2}{|c|}{ SimPlant S/W } & \multicolumn{2}{|c|}{ R2GATE S/W } & \multirow{2}{*}{$P$ value } \\
\hline & & Mean & $\mathrm{SD}$ & Mean & $\mathrm{SD}$ & \\
\hline A & Ease of access button in programs & 3.58 & 0.77 & 3.42 & 0.65 & 0.25 \\
\hline $\mathrm{B}$ & Ease of importing a CT file & 3.92 & 0.65 & 3.83 & 0.81 & 0.58 \\
\hline $\mathrm{C}$ & Ease of Matching process on CT file & 3.50 & 0.97 & 3.92 & 0.87 & $0.03^{*}$ \\
\hline $\mathrm{D}$ & Ease of setting up the position of the dental implant & 3.92 & 0.77 & 3.75 & 0.84 & 0.31 \\
\hline $\mathrm{E}$ & Ease of transfer function for making a surgical guide & 3.92 & 0.28 & 3.67 & 0.75 & $0.03^{*}$ \\
\hline $\mathrm{F}$ & Ease of the step-by-step process about program & 3.58 & 0.50 & 3.67 & 0.63 & 0.47 \\
\hline G & Ease of panorama image process & 3.92 & 0.87 & 3.83 & 0.38 & 0.54 \\
\hline $\mathrm{H}$ & Convenience of implant manufacturer selection & 4.42 & 0.50 & 2.92 & 1.27 & $0.00^{* *}$ \\
\hline $\mathrm{I}$ & Ease of forming teeth image and controlling size and shape & 3.67 & 0.63 & 3.00 & 0.83 & $0.00^{* *}$ \\
\hline $\mathrm{J}$ & Ease of expansion and contraction of the radiograph & 3.50 & 0.65 & 3.33 & 0.63 & 0.21 \\
\hline
\end{tabular}

* Statistically significant difference $(P<0.05)$.

**Statistically significant difference $(P<0.01)$. 


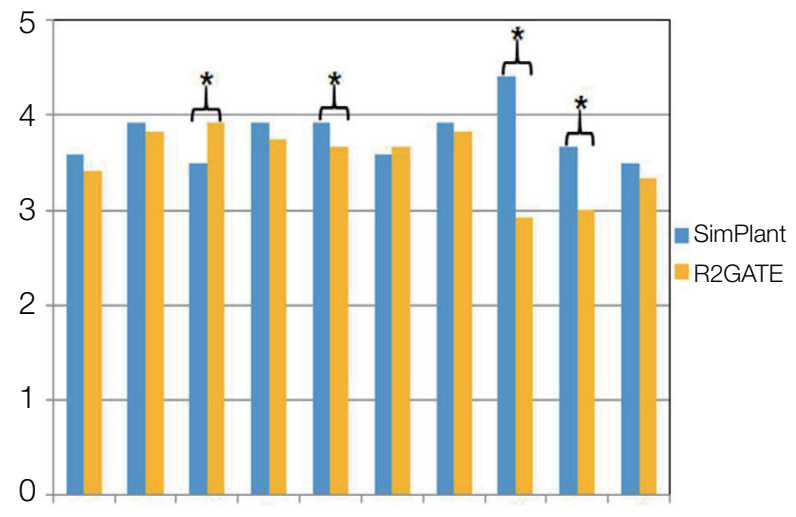

A $B$ C C D $\quad$ E $F \quad G \quad H \quad l \quad J$

Fig. 3. Design and ease of surgical guide making program. The blue is SimPlant software and yellow is R2GATE software in the graph.

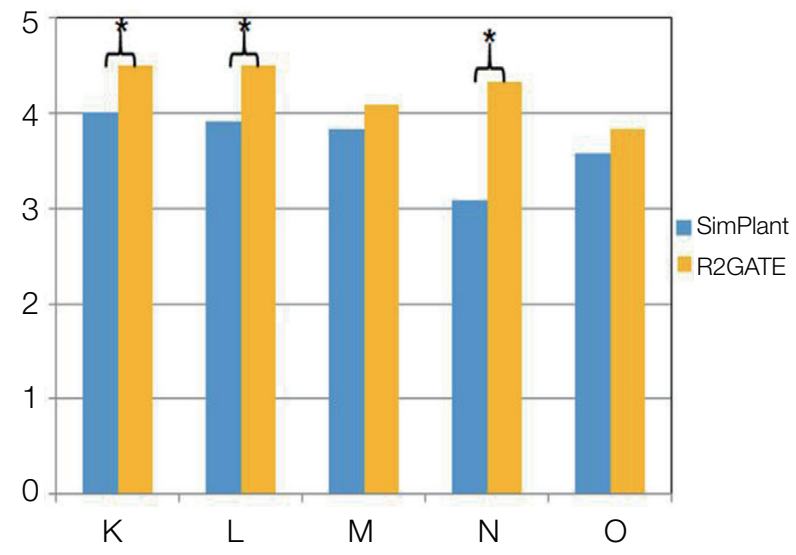

Fig. 4. Design and ease of surgical guide. The blue is SimPlant software and yellow is R2GATE software in the Figure.

Table 3. Subjects on the evaluation to the design and ease of surgical guide

\begin{tabular}{|c|c|c|c|c|c|c|}
\hline \multirow{2}{*}{ Option } & \multirow{2}{*}{ Composition } & \multicolumn{2}{|c|}{ SimPlant S/W } & \multicolumn{2}{|c|}{ R2GATE S/W } & \multirow{2}{*}{$P$ value } \\
\hline & & Mean & $\mathrm{SD}$ & Mean & $\mathrm{SD}$ & \\
\hline K & $\begin{array}{l}\text { Manufactured guide has a suitable form for application to } \\
\text { the clinical }\end{array}$ & 4.00 & 0.71 & 4.50 & 0.51 & $0.00^{* *}$ \\
\hline $\mathrm{L}$ & $\begin{array}{l}\text { The retention and stability is good when mounting the } \\
\text { surgical guide }\end{array}$ & 3.92 & 0.87 & 4.50 & 0.65 & $0.00^{* *}$ \\
\hline M & Well induce direction of the guide drill & 3.83 & 0.56 & 4.08 & 0.77 & 0.07 \\
\hline $\mathrm{N}$ & Possible to control the depth of the guide drill & 3.08 & 0.50 & 4.33 & 0.48 & $0.00 * *$ \\
\hline $\mathrm{O}$ & Usable immediately prosthesis & 3.58 & 0.87 & 3.83 & 0.69 & 0.12 \\
\hline
\end{tabular}

**Statistically significant difference $(P<0.01)$.

드의 형태에 대한 사용자의 만족도", "장착 시 유지력과 안정성” 그리고 “가이드 드릴의 깊이 제어성" 부분에서 R2GATE 군이 유의하게 큰 값을 보여 주었다 $(P<0.05$, Table 3, Fig. 4)

또한, Surgical guide 시스템을 활용 시 연구대상이 고 려하는 문제의 우선순위 부분을 분석한 결과 “프로그 램의 디자인 용이성”에서 연구대상의 $50 \%$ (6명)가 5점 을 선택하였고, "가이드 시스템의 사용 시 비용" 문항 에서도 50\% (6명)가 5점을 선택하였다. "임플란트의 식 립 적합성” 부분에서는 연구대상의 $91.7 \%$ (11명)가 1점 을 선택하였다. 전체적인 만족도는 R2GATE 군(7.33 \pm 1.26)이 SimPlant 군(6.67 \pm 1.26$)$ 보다 더 높은 것으로 나 타났다 $(P<0.05$, Fig. 5).

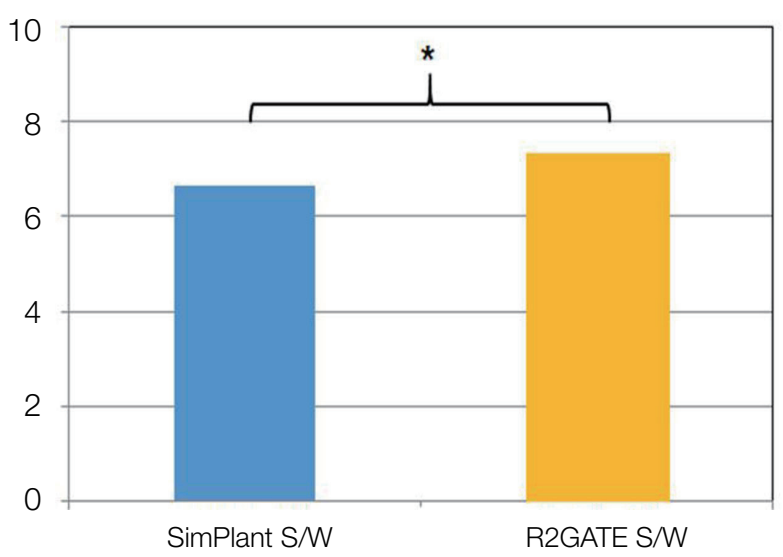

Fig. 5. Subjects on the evaluation to the design and ease of surgical guide and making program. The blue is SimPlant system and red is R2GATE system in the graph. 


\section{고찰}

본 연구는 SimPlant와 R2GATE 두 가지 수술용 가이 드 시스템의 인터페이스, 제작된 수술용 가이드의 디자 인과 편의성, 수술용 가이드 활용 시 중요도에 대한 만 족도를 설문 조사하여 비교평가 하고자 하였다.

두 종류의 임플란트 가이드 시스템과 제작된 가이드 의 비교연구(comparative study)를 하기 위해 술자는 동 일한 컴퓨터, 같은 공간에서 동시에 프로그램과 수술용 가이드에 대해 평가하였다. 비교법은 성질이 비슷한 두 가지 또는 그 이상의 물체를 서로 비교하여 어느 한쪽을 강조하는 방법이며, 암묵지(tacit knowledge)를 가장 효 과적으로 설명할 수 있는 방법이다. ${ }^{10}$ 하나의 물체만 평 가를 하게 되면 특이한 차이를 가지는 의미를 찾기 어려 운 반면, 비슷한 물체를 동시에 평가함으로써, 서로간의 특이점을 찾을 수 있는 점이 비교연구의 장점이다. 또 한, 본 연구는 서로 다른 두 종류의 수술용 가이드와 프 로그램을 동시에 비교하여 상대적인 우열 비교를 할 수 있었다.

임플란트 가이드 시스템의 디자인과 편의성에 대 한 결과를 보면 “CT 모형의 정합 편의성” 부분에서 R2GATE 군의 만족도가 우수하게 나타났고, 기타 대부 분 문항을 분석한 결과에 따르면 SimPlant 군이 더 높은 만족도 평가를 나타냈다. 이러한 결과는 SimPlant가 상 대적으로 오랫동안 임상에 적용되어 왔고, 보다 많은 사 용자들의 피드백을 받아 프로그램의 기능이나 편의성 면에서 우수한 결과가 나타난 것으로 사료된다. 즉, 국 내산 시스템인 R2GATE는 최근 완성된 소프트웨어로 기반 구축 단계이고 사용자가 국내에 한정되어 있어 이 러한 결과를 나타냈을 것이라고 생각된다.

두 가지 시스템에 의해 제작되어진 수술용 가이드의 디자인, 편의성 만족도 결과는 R2GATE가 통계학적으 로 유의한 높은 점수를 받았다는 것을 알 수 있었다. 이 는 R2GATE 수술용 가이드의 구조상 임플란트 drill의 shank부분을 가이드하는 특성이 있어 drill의 방향과 깊 이를 동시에 제어 할 수 있는 특징이 있기 때문이라고 생각된다. 이러한 R2GATE 수술용 가이드의 형태는 치 과의사들에게 높은 진료 효율과 우수한 편의성을 제공 하며 특히, 임플란트 식립 경험이 부족한 초심자가 더욱 선호할 것으로 간주된다.

전체적인 만족도의 평가에서는 R2GATE가 더 높은 점수로 우수한 결과를 나타냈다. 임플란트 가이드 시스
템의 디자인과 편의성 만족도 결과에서 SimPlant가 더 좋은 결과를 나타냈지만, 두 가지 수술용 가이드 시스템 모두 컴퓨터을 이용하여 수술 전 진단을 하고 디자인을 하는 과정을 술자가 직접 진행하는 것이 아니라 대부분 프로그램 회사에서 대행함으로써 프로그램의 디자인과 편의성 만족도 결과가 전체적인 결과에 영향을 주지 않 은 것으로 사료된다.

수술용 가이드 시스템을 활용 시 술자가 고려하는 문 제의 우선순위 부분에 대한 결과에서는 술자는 프로그 램의 편의성과 가이드의 비용에 대한 관심이 높았다. 이 러한 결과는 임플란트 환자의 경제적 요소와 술자의 제 품 지출 비용 부분에서 높은 관심을 받을 수밖에 없었다 고 생각된다. 그러나 흥미로운 점으로 당연히 중요하게 고려할 것이라고 추측했던 “임플란트의 식립 적합성”에 대한 연구대상의 평점은 $91.7 \%$ 가 1점을 선택한 것으로 나타났다. 이는 수술용 가이드 시스템은 술자가 우려하 지 않아도 될 정도로 수술용 가이드 사용자들이 충분한 신뢰성을 갖고 있었기 때문일 것으로 생각된다.

본 연구의 한계점으로는 연구 대상의 수가 적다는 것 과 두 가지 시스템만 선정하여 비교하였다는 것이다. 프 로그램과 수술용 가이드를 같은 시간, 같은 공간에서 사 용해 보고 평가한 후 비교해야 하는 연구이므로 연구 대 상을 모집하는데 어려움이 있었다. 본 연구에 참여한 치 과의사가 모든 술자를 대표할 수 없기 때문에 연구의 타 당성과 신뢰성을 높이기 위해서는 향후, 더 넓은 지역의 더 큰 표본이 필요하고 생각된다. 또한, SimPlant 시스템 은 수술용 가이드 시스템의 원조라고 볼 수 있으나 단순 히 이 한 가지 시스템과의 비교로 얻은 결과로 국산 시 스템을 평가하기 어려울 것으로 사료되며, 추후 많은 연 구 대상과 다양한 임플란트 가이드 시스템을 비교평가 함으로써 보다 신뢰성 있는 연구가 필요할 것이다.

\section{결론}

본 연구의 한계 내에서 아래와 같은 결론을 얻을 수 있었다.

1. R2GATE 시스템으로 제작된 수술용 가이드는 임 상에 널리 사용 할 만 한 사용자의 만족도를 가진다.

2. R2GATE 시스템으로 제작된 수술용 가이드는 drill의 길이와 방향을 동시에 guide 할 수 있어 임 플란트 식립 경험이 부족한 치과의사에게 적극 추 천된다. 


\section{Acknowledgements}

본 연구는 의료기기 유망제품 사용자(의료기관) 테스 트 지원사업("영상분석장치소프트웨어 R2GATE의 임 상테스트 지원”)의 연구지원비에 의해 작성되었습니다 (2014. 10 - 2015.03).

\section{Orcid}

Min-ho Hong http://orcid.org/0000-0002-6456-2200

Ming-Xu Jin http://orcid.org/0000-0002-0744-2210

Du-Hyeong Lee http://orcid.org/0000-0003-2803-7457

Kyu-Bok Lee http://orcid.org/0000-0002-1838-7229

\section{References}

1. Hounsfield GN. Computerized transverse axial scanning (tomography). 1. Description of system. Br J Radiol 1973;46:1016-22.

2. Schmuth GP, Freisfeld M, Köster O, Schüller H. The application of computerized tomography (CT) in cases of impacted maxillary canines. Eur J Orthod 1992;14:296-301.

3. Schulze D, Heiland M, Thurmann H, Adam G. Radiation exposure during midfacial imaging using 4- and 16-slice computed tomography, cone beam computed tomography systems and conventional radiography. Dentomaxillofac Radiol 2004;33:83-6.

4. Becker CM, Kaiser DA. Surgical guide for dental implant placement. J Prosthet Dent 2000;83:24851.

5. George FM, Chan HL, Razzoog ME, Oh TJ. Fabrication of a cast-based implant surgical guide using guide sleeves. J Prosthet Dent 2011;106:409-12.

6. Valente F, Schiroli G, Sbrenna A. Accuracy of computer-aided oral implant surgery: a clinical and radiographic study. Int J Oral Maxillofac Implants 2009;24:234-42.

7. Ruppin J, Popovic A, Strauss M, Spüntrup E, Steiner A, Stoll C. Evaluation of the accuracy of three different computer-aided surgery systems in dental implantology: optical tracking vs. stereolithographic splint systems. Clin Oral Implants Res 2008;19:70916.

8. Park JM, Heo SJ, Park EJ. Comparative study on clearance between drilling and bushing of various implant guide systems. Implantology 2014;18:194202.

9. Lee DH, Lee KB. The comparative study of user satisfaction on various implant engine system. J Dent Rehabil Appl Sci 2014;30:9-15.

10. Lijphart A. II. The comparable-cases strategy in comparative research. Comparative Political Studies 1975;8:158-77. 


\section{컴퓨터 단층 촬영을 기반으로 한 임플란트 가이드 시스템에 대한 임상가의 만족도 분석}

\section{홍민호 $^{\dagger}$, 김명욱 $^{\dagger}$, 이두형, 이규복*}

경북대학교 치과대학 치과보철학교실, 첨단치과의료기기개발연구소

목적: 본 연구에서는 Simplant와 R2GATE 두 가지 수술용 가이드 시스템의 인터페이스(interface)에 대한 만족도, 제작 된 수술용 가이드의 디자인과 편의성, 수술용 가이드 활용 시 중요도에 대한 만족도를 설문조사하여 비교평가 하고자 하였다.

연구 재료 및 방법: 두 가지 시스템으로 제작된 수술용 가이드(surgical guide)를 치아모형에 각각 장착한 상태에서 임플 란트 수술 과정을 모의하였다. 모의 수술이 끝난 뒤 연구대상에게 만족도에 관한 설문지를 작성하도록 하였다. 작성된 설문지를 회수하여 각 문항에 대한 데이터를 정리하고 통계 프로그램 SPSS 20.0 (IBM)를 이용하여 분석하였다.

결과: 전체적인 만족도는 R2GATE 군(7.33 \pm 1.26$)$ 이 SimPlant 군(6.67 \pm 1.26$)$ 보다 더 높은 것으로 나타났다 $(\alpha=$ 0.05).

결론: R2GATE 시스템으로 제작된 수술용 가이드는 임상에 널리 사용 할 만 한 사용자의 만족도를 나타내었다. 또한, R2GATE 시스템으로 제작된 수술용 가이드는 drill의 길이와 방향을 동시에 guide할 수 있어 임플란트 식립 경험이 부 족한 초심자에게 적극 추천된다.

(구강회복응용과학지 2015;31 (3): 178-85)

주요어: 수술용 가이드; 임플란트 가이드 시스템; 설문조사

*교신저자: 이규복

(41904)대구시 중구 달구벌대로 2177 경북대학교 치의학대학원 치과보철학교실

Tel: 053-600 7674 | Fax: 053-426-7661 | E-mail: kblee@knu.ac. kr

접수일: 2015년 5월 26일 | 수정일: 2015년 7월 23일 | 채택일: 2015년 7월 27일

${ }^{\dagger}$ 이 저자들은 본 연구에 대한 기여도가 같다. 